\title{
PROPOSAL OF A TIMER CONTROLLER WITH CONSTANT SWITCHING FREQUENCY AND POWER FACTOR CORRECTION
}

\author{
Marcos T. Galelli, Márcio S. Vilela, Ernane A. A. Coelho, João Batista Vieira Jr.*, \\ João Carlos de Oliveira, Luiz Carlos de Freitas and Valdeir J. Farias \\ Power Electronics Research Group \\ Federal University of Uberlândia - Bloco 3N \\ Av. João Naves de Ávila, 2121 \\ 38400-902 - Uberlândia-MG - Brazil \\ E-mail: batista@ufu.br
}

\begin{abstract}
The proposal of this paper is to introduce a new control technique for power factor correction in acdc converters. It combines the advantages of conventional hysteresis control strategy and the prominent characteristics of constant switching frequency. The fundamental idea consists of determining the ideal time interval that exists between the moment when the input current crosses with the reference current and the converter commutation. Thus the input current can oscillate simetrically around the reference current with constant frequency of operation. The operating principles, theoretical analysis and simulation results on a single-phase Boost converter are presented to validate the proposal.
\end{abstract}

Keywords - constant switching frequency, low harmonic distortion, power factor correction.

\section{INTRODUCTION}

One notices when one looks at Electrical Engineering applications, the growing number of nonlinear loads such as diode or thyristor rectifiers, switch-mode power supplies and adjustable speed drives, generate harmonic currents causing various problems to other equipment connected to the point of common coupling. Typical problems are overheated machines, transformers and power cables, current flow in the neutral conductor, flicker effects, and malfunctioning of sensitive devices. The reduction of the harmonic contents and also the high power factor are desirable aspects in ac-dc converters, as they have the potential for reducing harmonic sources which is a good operational characteristic from the point of view of power quality [1].

For such aspects, several standards have been proposed to normalize and limit harmonic pollution, such as IEEE Std 519 and IEC 61000-3-2. Throughout the years, switching techniques have been introduced to static converters in order to minimize such disturbances, with two strategies becoming popular i.e. PWM and hysteresis modulation. The hysteresis control introduces a minor error in the average input current and provides better dynamic response than the PWM control, but an inherent drawback is the variable switching frequency. Therefore the control circuit has to be designed for a large band, otherwise it will cause low frequency harmonics [2].

Manuscript received on October 28, 2005; first revision on February 6, 2006; second revision, on April 17, 2006.

Recommended by the Editor José Antenor Pomilio
In light of this limitation, this paper introduces a novel control technique that allows ac-dc converters to operate with constant switching frequency, except when the reference current crosses with zero reference, and with the advantages of a common hysteresis control strategy, the THD and harmonic content are less than other techniques that operate with constant switching frequency.

\section{TIME CONTROLLER WITH POWER FACTOR CORRECTION}

The basic idea of the proposed technique is to determine the ideal time interval between the switch commutation and the moment when the input current, IL, crosses the reference current, Iref. With these intervals, it is possible to build a timer circuit to control the commutation of switches with constant frequency, so that the triangles abc and cde have the same area and the medium value of IL, Fig. 1, will be Iref. Fig. 1 shows the behavior of the input current along an incremental time interval, where the reference current is practically constant, which is possible since the switching frequency is much greater than the line frequency.

This type of strategy can be applied to most single-phase ac-dc converters, without any essential change to the original topology [3]. For this study, a conventional hard-switched Boost converter operating in continuous conduction mode is chosen due to simplicity, as it has only two operating stages.

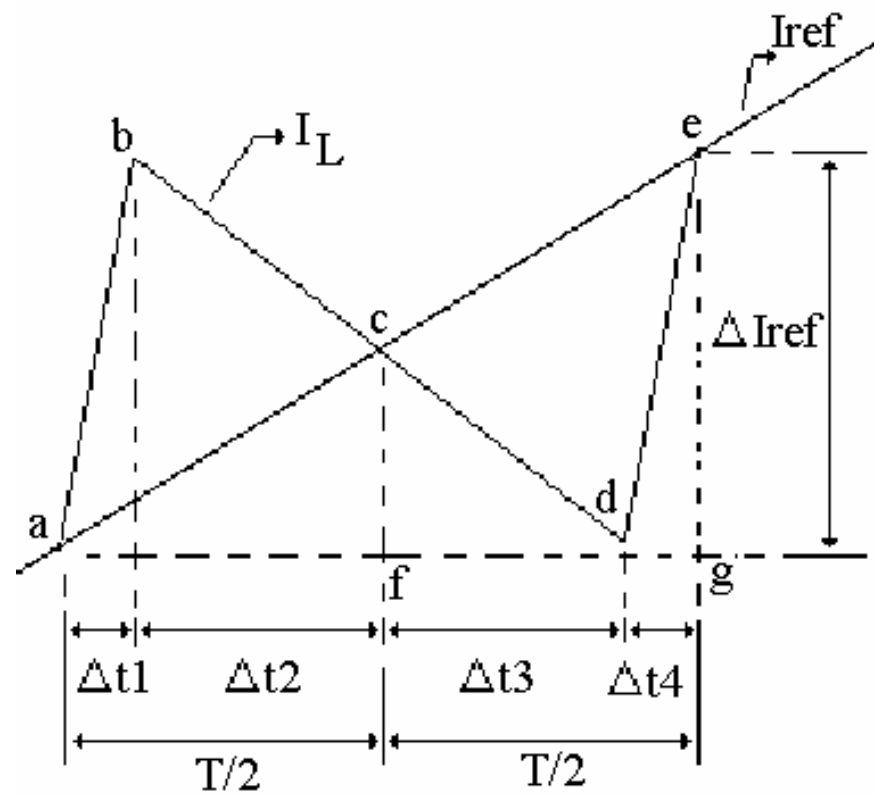

Fig. 1. Current profile along a switching period. 


\section{MATHEMATICAL ANALYSIS}

In order to analyze the proposed control strategy, the circuit shown in Fig. 2 must be considered, where it can be seen that the full bridge converter operation can be defined in two distinct stages. Voltage $V_{x}$ in the first and second stages is defined as $V_{x l}$ and $V_{x 2}$, respectively. Such values depend on the type of the converter in question. For the full-bridge topology, voltages $V_{x 1}$ and $V_{x 2}$ will be respectively $V_{o}$ and $V_{o}$. For the boost converter, voltages $V_{x 1}$ and $V_{x 2}$ will be $V_{o}$ and null, respectively. However, independent of the topology, voltage $V_{x l}$ will always be greater than the input voltage, and voltage $V_{x 2}$ is less than the input voltage or null. Additionally, if the switching frequency is considered much greater than the line frequency, the behavior of the inductor current can be described according to Fig. 1, which corresponds to an ideal situation i.e. triangles $\mathrm{ABC}$ and $\mathrm{CDE}$ have the same area. To obtain this, it is necessary to determine time intervals $\Delta t_{1}$ and $\Delta t_{3}$, which correspond to the exact moments when the switch is commutated. Intervals $\Delta t_{1}$ and $\Delta t_{3}$ are determined as a function of the circuit parameters, in order to maintain constant switching frequency.

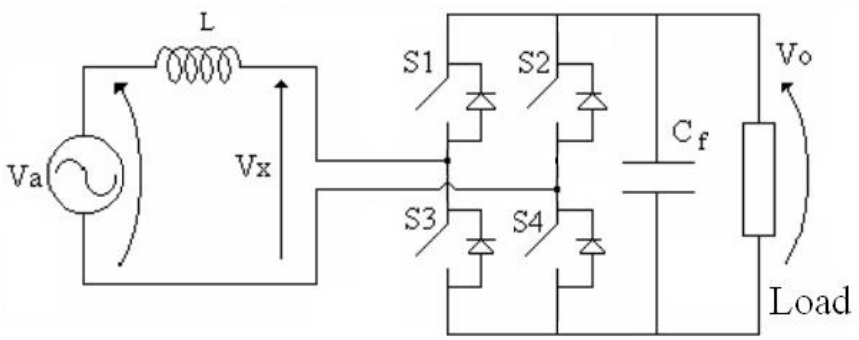

Fig. 2. Full Bridge converter with two operating stages.

Expressions (1) and (2) represent the increasing and decreasing rates of the input current, respectively.

$$
\begin{aligned}
& I_{L}=\frac{\int\left(-V_{X 2}+V_{a}\right) d t}{L} \\
& I_{L}=\frac{\int\left(-V_{X 1}+V_{a}\right) d t}{L}
\end{aligned}
$$

Within these aspects, the output voltage is constant and the reference current variation is considered linear. In addition to this, the increasing and decreasing rates of the inductor current can be considered constant. Therefore triangles $\mathrm{ABC}$ and $\mathrm{CDE}$ have the same area and the following expressions are valid:

$$
\begin{aligned}
& \Delta t_{2} \cong \Delta t_{3} \\
& \Delta t_{1} \cong \Delta t_{4}
\end{aligned}
$$

Where:

$\Delta t_{1}$ - represents the time interval where the current derivative is positive, from the crossing point with the reference current to the instant of commutation;
$\Delta t_{2}$ - represents the corresponding time interval where the current derivative is negative from the instant of commutation to the crossing point with the reference current;

$\Delta t_{3}$ - represents the corresponding time interval where the current derivative is negative from the crossing point with the reference current to the instant of commutation;

$\Delta t_{4}$ - represents the corresponding time interval where the current derivative is positive from the instant of commutation to the crossing point with the reference current.

Intervals $\Delta t_{1}$ and $\Delta t_{3}$ determine the moment to commutate the switches. Time interval $\Delta t_{1}$ can be calculated from (5) and (6).

$$
\Delta t_{1}+\Delta t_{2}=T / 2
$$

Considering, in fig. 1, that triangle AFC is similar to triangle AGE, the inductor current variation in a $T / 2$ time interval is

$$
\int_{t}^{t+\Delta t_{1}} \frac{\left(-V_{X 2}+V_{a}\right) d t}{L}+\int_{t+\Delta t_{1}}^{t+T / 2} \frac{\left(-V_{X 1}+V_{a}\right) d t}{L}=\frac{\Delta I_{r e f}}{2}
$$

Where:

$\Delta I_{\text {ref }}$ is the reference current variation in a switching period;

$T$ is the switching period.

Assuming that current $I_{r e f}$ is linear along the switching period, $\Delta I_{\text {ref }}$ can be calculated as:

$$
\Delta I_{r e f}=T \frac{d I_{r e f}}{d t}
$$

Finally, from the previous expressions, the generic equation to interval $\Delta_{t l}$ is given as:

$$
\Delta_{T 1}=\frac{T}{2\left(V_{X 1}-V_{X 2}\right)}\left(V_{X 1}-\frac{2}{T} \int_{t}^{t+T / 2} V_{a} d t+\frac{L \Delta I_{r e f}}{T}\right)
$$

The same procedure can be used to calculate $\Delta t_{3}$. The Full Bridge converter equation (8) can be simplified as follows:

$$
\Delta t_{1}=\frac{T}{4 V_{0}}\left(V_{0}-V_{a}+L \frac{d I_{r e f}}{d t}\right)
$$

Analogously, $\Delta t_{3}$ can be obtained from (10).

$$
\Delta t_{3}=\frac{T}{4 V_{0}}\left(V_{0}+V_{a}-L \frac{d I_{r e f}}{d t}\right)
$$

From time intervals $\Delta t_{1}$ and $\Delta t_{3}$, it is possible to develop a circuit that allows one switch to be controlled (or more switches, in some topologies) with constant frequency, emulating hysteresis band. Therefore the behavior of the input current is represented in Fig. 3, where time intervals $\Delta t_{l}$ and $\Delta t_{3}$, maintain the input current between two reference waveforms. Analogously to the hysteresis control, these two reference currents can be calculated from equations (11) and (12), respectively. 


$$
\begin{gathered}
I_{\text {ref (up) }}=\frac{1}{L} \int_{0}^{\Delta_{T 1}}\left(V_{0}+V_{a}-L \frac{d I_{r e f}}{d t}\right) d t+I_{r e f} \\
I_{r e f(\text { low })}=\frac{1}{L} \int_{0}^{\Delta_{T 3}}\left(-V_{0}+V_{a}-L \frac{d I_{r e f}}{d t}\right) d t+I_{r e f}
\end{gathered}
$$

The reference current is the same parameter in expressions (11) and (12), which can be simplified and adequately represented as (13) and (14), respectively.

$$
\begin{gathered}
I_{r e f(\text { up })}=\frac{1}{L}\left(V_{0}+V_{a}-L \frac{d I_{r e f}}{d t}\right) \Delta_{T 1}+I_{r e f} \\
I_{r e f(l o w)}=\frac{1}{L}\left(-V_{0}+V_{a}-L \frac{d I_{r e f}}{d t}\right) \Delta_{T 3}+I_{r e f}
\end{gathered}
$$

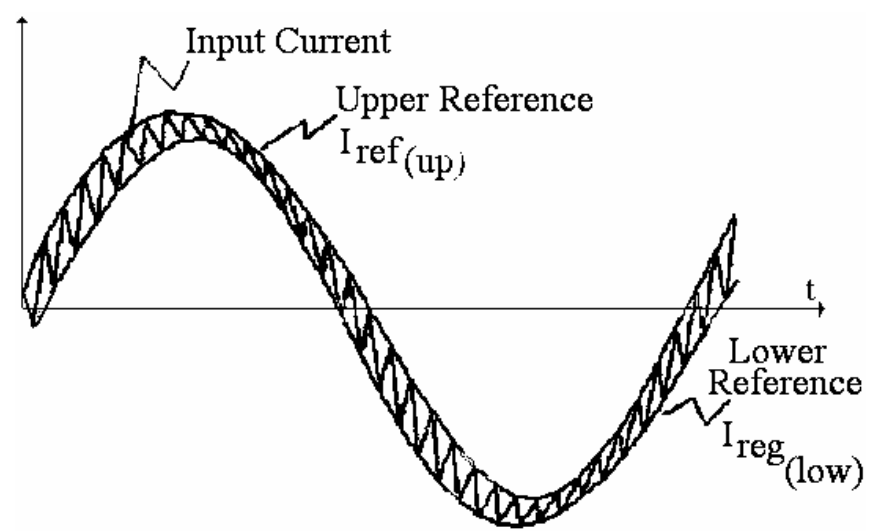

Fig.3. Input current behavior.

\section{BOOST CONVERTER}

The single-phase boost converter shown in Fig. 4 has just two operating stages. When $S_{l}$ switch is off, the voltage across the filter inductor is $\left(V_{a}-V_{o}\right)$, otherwise it is $V_{a}$. The simplified control circuit used in a Boost converter is shown in fig. 4 too.

For this converter, the expressions corresponding to time intervals $\Delta t_{1}$ and $\Delta t_{3}$ i.e. (9) and (10) can be written as:

$$
\begin{gathered}
\Delta_{T 1}=\frac{T}{2 V_{0}}\left(V_{0}-\frac{2}{T} \int_{t}^{t+T / 2}\left|V_{a}\right| d t+\frac{L d I_{r e f}}{T}\right) \\
\Delta_{T 3}=\frac{T}{2 V_{0}}\left(\frac{2}{T} \int_{t}^{t+T / 2}\left|V_{a}\right| d t-\frac{L d I_{r e f}}{T}\right)
\end{gathered}
$$

Both equations can be approximated to expressions 17 and 18 , respectively:

$$
\begin{gathered}
\Delta_{T 1}=\frac{T}{2 V_{0}}\left(V_{0}-\left|V_{a}\right|+\frac{L d I_{r e f}}{T}\right) \\
\Delta_{T 3}=\frac{T}{2 V_{0}}\left(\left|V_{a}\right|-\frac{L d I_{r e f}}{T}\right)
\end{gathered}
$$

Time intervals $\Delta t_{2}$ and $\Delta t_{4}$ can be calculated analogously, but they are not necessary in the control development, because they are not directly involved in the process itself.

Figure 5 shows the main control block. The operation of this circuit is quite simple. The objeticve is to impose an ideal situation i.e. triangles $\mathrm{ABC}$ and $\mathrm{CDE}$ must have the same area, so the IL current will oscilate simetrically around the reference current Iref. With this, it will be possible to obtain small THD and harmonic content in the imposed current. First, it is necessary to create the reference current signal Iref. In fig. 4 it can be seen that Iref is a function of Va that provides the sinusoidal waveform to Iref, as well as a function of the output voltage error, to enable the control to regulate the output voltage. The block $\mathrm{X}$ is a multiplier. The process to obtain Iref is similar to the process used in Unitrode IC 3854.

Also, It is necessary to create two voltage signals, $V_{\Delta t 1}$ and $\mathrm{V}_{\Delta t 3}$, fig. 4. These signals are proportional to rectfied input voltage $\mathrm{Va}$, to output voltage Vo, and to the differential Iref current. Adding these three signals, in a way shown in fig. $4, \mathrm{~V} \Delta t_{1}$ and $\mathrm{V} \Delta t_{3}$ signals are obtained. The parameter K2 is proportional to inductor $\mathrm{L}$ and constant $\mathrm{K} 1$, and the $\mathrm{K} 1$ value is chosen to keep voltages $V_{\Delta t 1} \mathrm{eV}_{\Delta t 3}$ within the voltage band used for the circuit control. Therefore parameter K1 can be defined as:

$$
K_{1} \approx \frac{T}{2 V_{o} L}
$$

Considering the "a" point in fig. 1, when the inductor current IL crosses with the reference current Iref in ascendant direction, at this moment, switch $\mathrm{S} 1$ is on, and the output comparator 1 turns to high level, "1", so the AND gate 1 turns to "1" too. The AND gates 2 and 4 remain at low level, and the comparator 3 is off, as shown in fig. 6 .

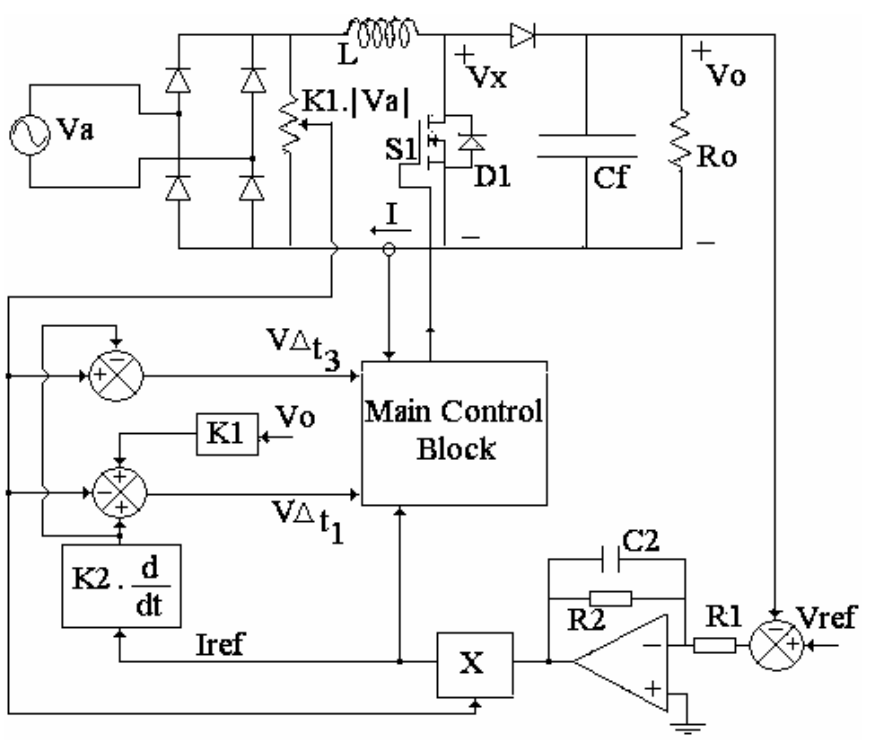

Fig. 4. Simplified block diagram using timer control applied to a boost converter.

The high level in AND gate 1 sets the OR gate to level " 1 ", enabling the ramp generator. The ramp generator creates a voltage ramp with inclination $\left(2 V_{o} / T\right)$, until this voltage reaches $V_{\Delta t 1}$. When Vramp $>\mathrm{V}_{\Delta t}$, the outputs of comparator 
2 and AND Gate 3 turn to "1". The $\bar{Q}$ output "flip-flop" turns to " 0 ", turning off the $\mathrm{S} 1$ switch. This finishes the $\Delta \mathrm{t} 1$ time interval, as shown in fig. 6 , where PS1 is the S1 gate pulse.

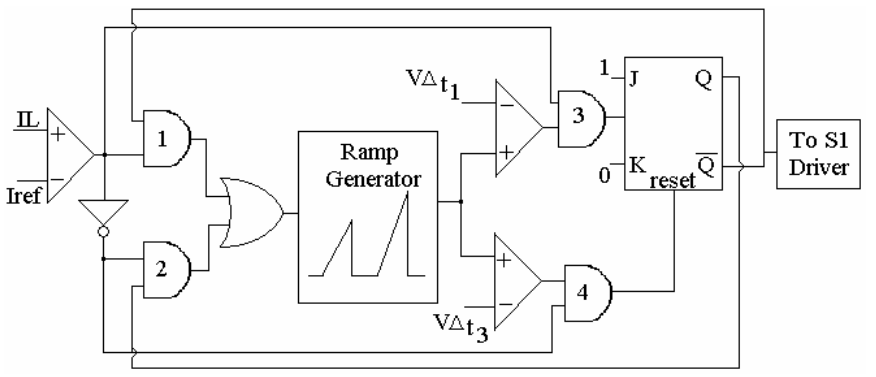

Fig 5. Block diagram of the main control circuit.

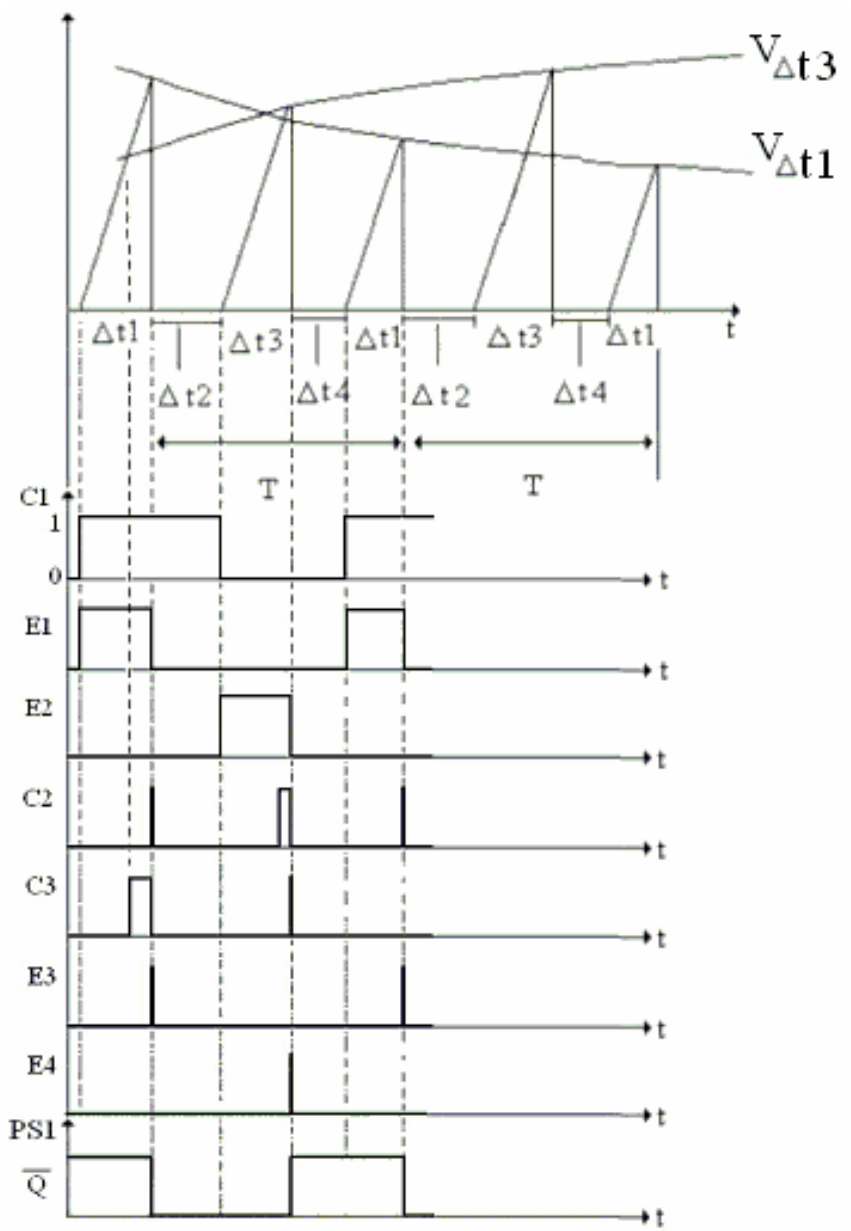

Fig 6. $\mathrm{V} \Delta t_{l}$ and $\mathrm{V} \Delta t_{3}$ waveforms and logic signal control.

Following this, $\bar{Q}=0$ leads the output of the AND gate 1 to " 0 ", resetting the OR gate, and turning off the ramp generator. With Switch S1 off, the inductor current decreases until it crosses again with the reference current, in " $\mathrm{C}$ " point, fig. 1. So time interval $\Delta \mathrm{t} 2$ finishes and $\Delta \mathrm{t} 3$ time interval begins. Comparator 1 goes to " 0 ". This transition disables AND gates 1 and 3 , disabling comparator 2 . The AND gate 2 goes to " 1 ", enabling AND gate 4 to follow the comparator 3 state logic.

With IL < Iref, the OR gate output goes to "1" again, enabiling the ramp genetor. When the voltage ramp reaches $V_{\Delta t 3}$, Vramp $>\mathrm{V}_{\Delta t 3}$, the outputs of comparator 3 and AND

Gate 4 turn to "1" and the $\bar{Q}$ output "flip-flop" turns to "1", enabling the S1 switch and thus turning off the ramp generator. This finishes the $\Delta \mathrm{t} 3$ time interval and begins $\Delta \mathrm{t} 4$. After this moment, the inductor current increases until it crosses with the reference current, finishing $\Delta \mathrm{t} 4$ time interval and beginning a new switching cycle.

The ramp generator circuit is shown in fig. 7.

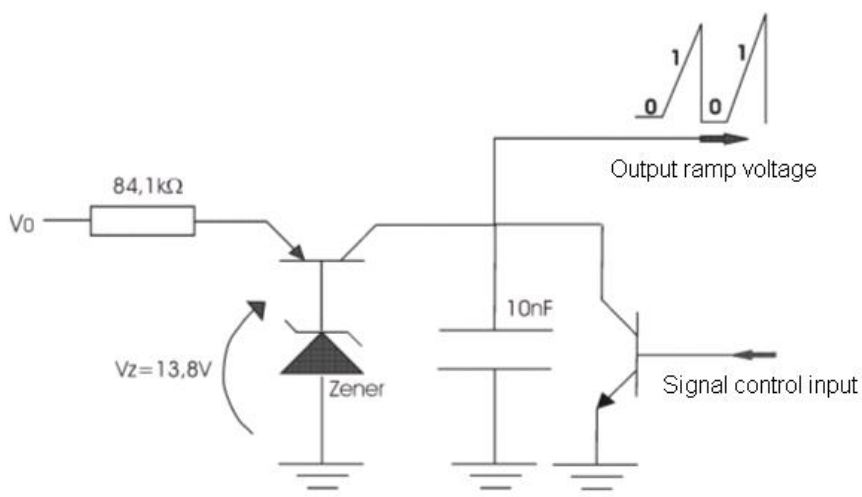

Fig 7. Ramp generator circuit.

This circuit determines the switching frequency. The $\mathrm{V} \Delta t_{1}$ and $\mathrm{V} \Delta t_{3}$ voltages values determine the voltage ripple in the capacitor. The switching frequency can be calculated in eq. 20 .

$$
f_{s}=\frac{I_{c}}{2 \times C \times \Delta V_{c}}
$$

\section{SIMULATION RESULTS}

Simulation tests were performed on a Boost converter to demonstrate the control strategy. Conventional hysteresis control was also implemented to establish an eventual comparison between both techniques. One must mention that in both cases the average switching frequency is basically the same. The parameters employed in the tests are specified in Table I.

Table I

Parameters set used in simulation tests

\begin{tabular}{|l|c|}
\hline \multicolumn{1}{|c|}{ Parameter } & Value \\
\hline Input voltage & $V_{i}=127 \mathrm{Vrms}$ \\
\hline Output voltage & $V_{0}=250 \mathrm{Vdc}$ \\
\hline Filter inductor & $L_{f}=1.73 \mathrm{mH}$ \\
\hline Filter capacitor & $C_{f}=1000 \mu \mathrm{F}$ \\
\hline Load current & $I_{o}=5.5 \mathrm{~A}$ \\
\hline Switching frequency & $f_{s}=20 \mathrm{kHz}$ \\
\hline Switch $S_{1}$ & IRFP460 \\
\hline Diodes & MUR1560 \\
\hline
\end{tabular}

Fig. 8 shows the input current waveform. 


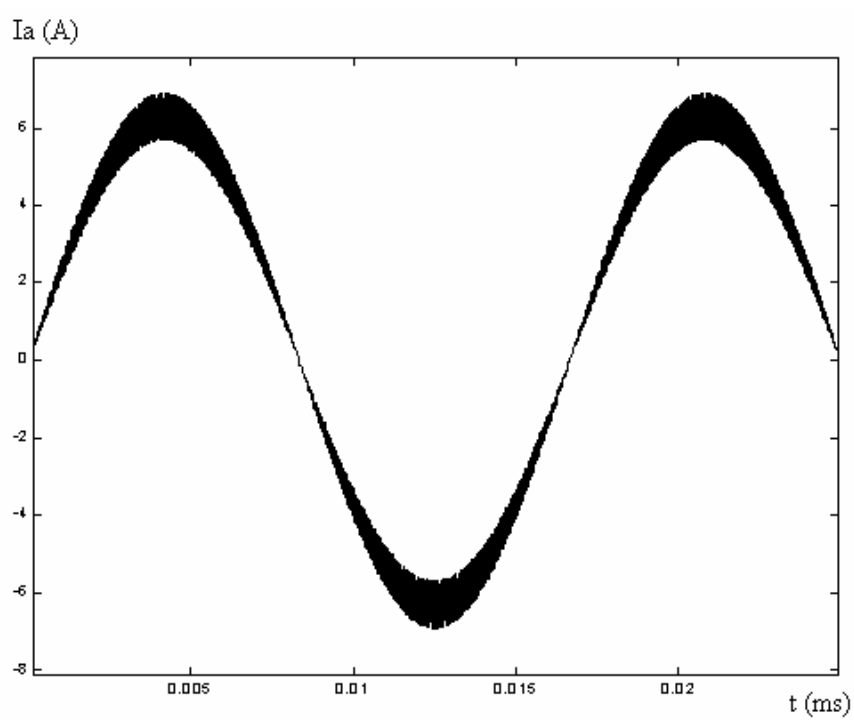

Fig 8. Input current waveform.

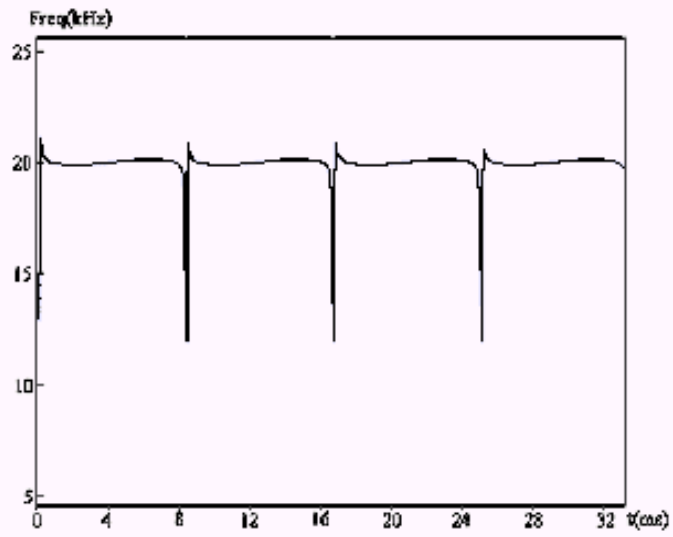

(a) Proposed Timer technique.

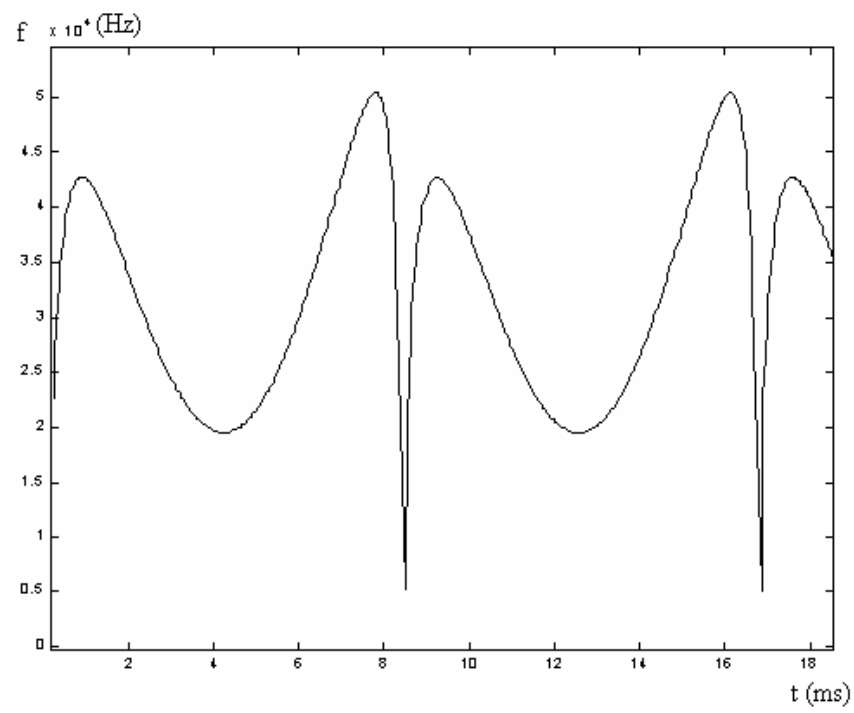

(b) Conventional hysteresis technique.

Fig. 9. Switching frequency oscillation.
Fig. 9 (a) and (b) compare the switching frequency oscillation in a Boost converter operating with the proposed technique and the conventional hysteresis strategy, respectively. In fig. 9 (a) the inductor current growth depends on the input voltage. When this voltage crosses with zero, and a new growth stage of the reference current begins, the inductor current $\mathrm{di} / \mathrm{dt}$ is less than the reference current $\mathrm{di} / \mathrm{dt}$, so the switch S1 must be on until IL reaches Iref. In this case, the switching frequency will decrease. It can be seen that the frequency variation in the conventional histeresis is greater than the proposed technique, fig. 9 (b) This large frequency variation makes it more difficult to filter the harmonic content, and the filter in this case is heavier and voluminous.

Fig. 10 (a) and (b) compare the input current harmonics amplitudes in the frequency domain with both control techniques. It can be seen that in 10 (a) the harmonic content is centered at $20 \mathrm{kHz}$ and can be easily filtered.

In fig. 10 (b) the harmonics are distributed in a range of $2 \mathrm{kHz}$ to $6 \mathrm{kHz}$. So, in this case, it is more difficult to filter the harmonic content, and a low pass filter must be used with a corner frequency of $600 \mathrm{~Hz}$.

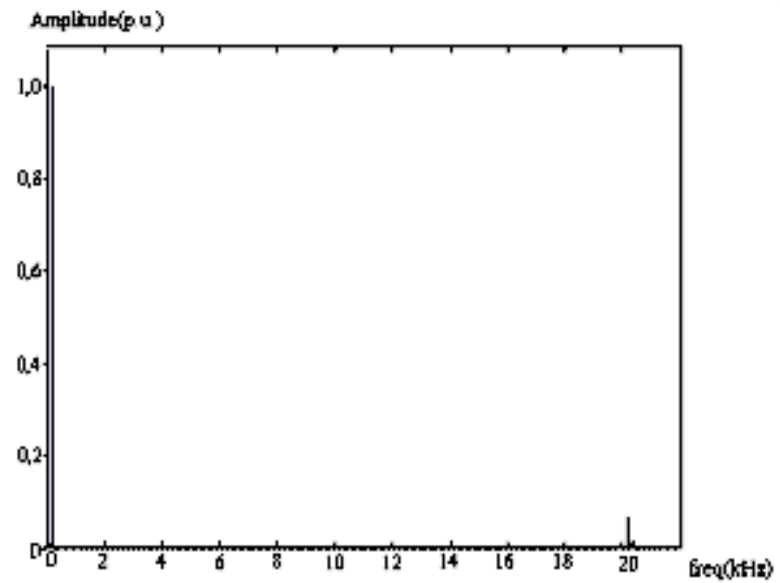

(a) Proposed Timer technique.

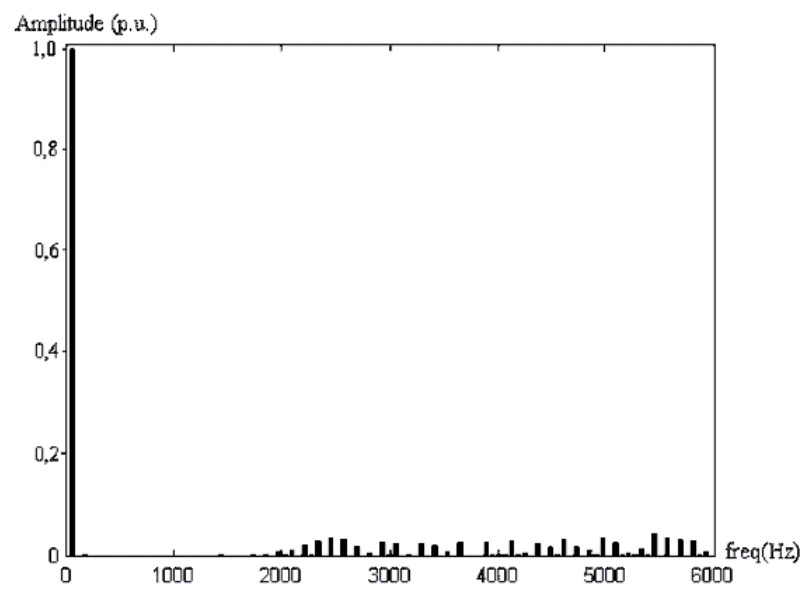

(b) Conventional hysteresis technique.

Fig. 10. Harmonic amplitudes in the frequency domain. 
Fig. 11 (a) and (b) compare the harmonic content as a function of the harmonic order. In fig 11 (a) it can be seen that there exists a third harmonic, $180 \mathrm{~Hz}$, with an amplitude of $0.5 \%$ of the fundamental amplitude. The THD in fig. 11 (a) is $0.55 \%$. In fig. 11 (b) the low frequency harmonics have low amplitudes, however the harmonic amplitudes increase rapidly a from the 22 nd harmonic. The THD in fig. 11. (b) is $3.7 \%$.

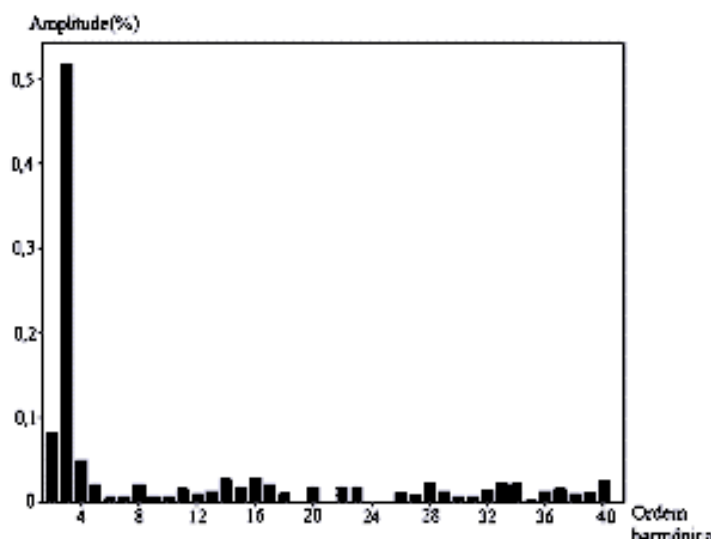

(a) Proposed Timer technique.

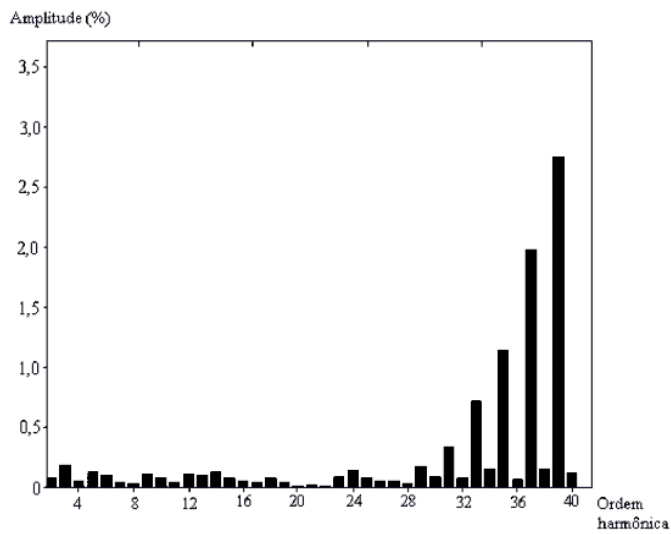

(b) Conventional hysteresis technique.

Fig. 11 Harmonic amplitude as a function of the harmonic order.

\section{EXPERIMENTAL RESULTS}

A Boost converter was experimentally developed and evaluated. The parameters employed in these tests are specified in Table II.

Table II

Parameters set used in simulation tests

\begin{tabular}{|l|c|}
\hline \multicolumn{1}{|c|}{ Parameter } & Value \\
\hline Input voltage & $V_{i}=127 \mathrm{Vrms}$ \\
\hline Output voltage & $V_{0}=250 \mathrm{Vdc}$ \\
\hline Filter inductor & $L_{f}=1.73 \mathrm{mH}$ \\
\hline Filter capacitor & $C_{f}=1000 \mu \mathrm{F}$ \\
\hline Load current & $I_{o}=5.5 \mathrm{~A}$ \\
\hline Switching frequency & $f_{s}=20 \mathrm{kHz}$ \\
\hline Switch $S_{1}$ & IRFP460 \\
\hline Diodes & MUR1560 \\
\hline
\end{tabular}

Fig. 12 proves the existence of a power factor correction. One obeserves a quasi-sinusoidal waveform to the $\mathrm{AC}$ input current for an input power of $600 \mathrm{~W}$.

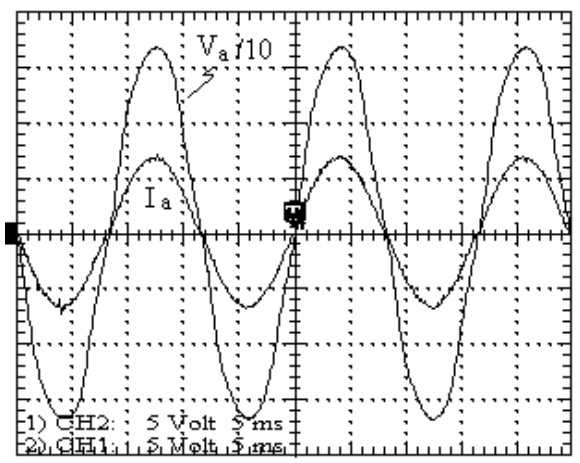

$\mathrm{va}(\mathrm{t}): 5 \mathrm{~V} / \mathrm{div} ; \mathrm{ia}(\mathrm{t}): 5 \mathrm{~A} / \mathrm{div}$; Time: $5 \mathrm{~ms} / \mathrm{div}$.

Fig. 12. Input voltage and input current waveforms.

Figs. 13 and 14 show the harmonic contents of the input voltage and input current, where voltage THD is $3.4 \%$ and current THD is $1.9 \%$.

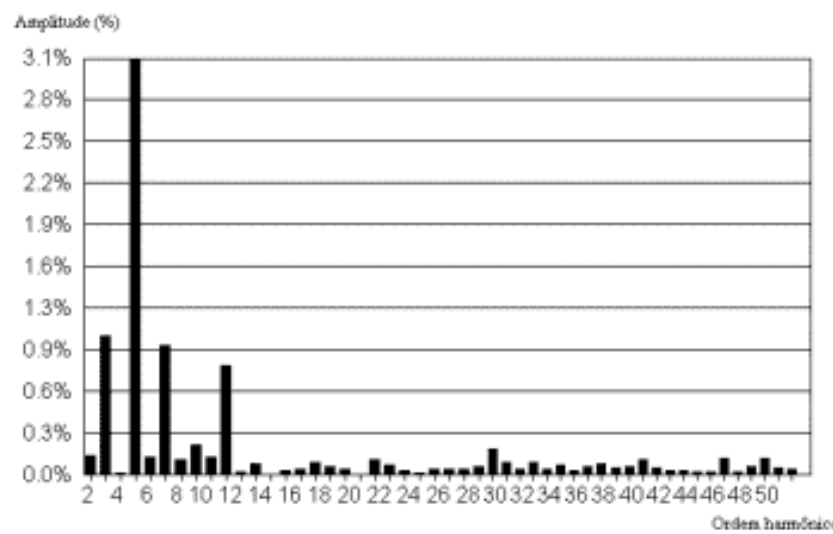

Fig. 13. Harmonic content of the input voltage.

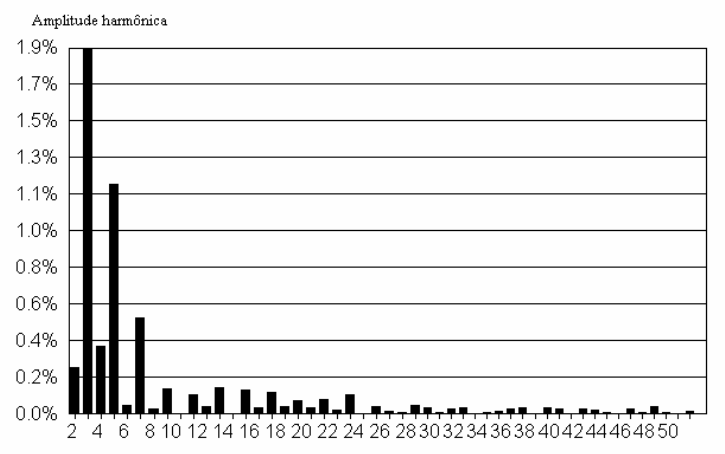

Fig. 14. Harmonic content of the input current.

Figs. 15 and 16 show details of output voltage and ramp voltage, and filter inductor current and ramp voltage, respectively. Fig. 16 shows clearly that the IL current increases linearly when $\Delta t 3$ time interval finishes, and decreases linearly when $\Delta t 1$ finishes. 


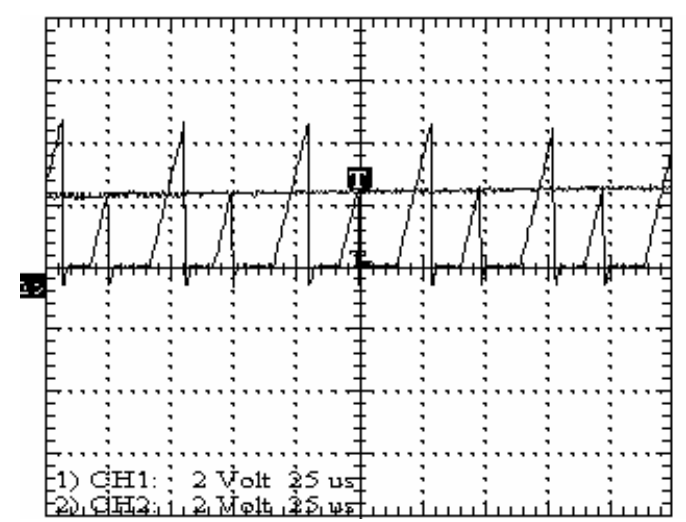

Ch1: 200V/div; Ch2: 2V/div; Time: $25 \mu$ div.

Fig. 15. Output voltage and ramp voltage.

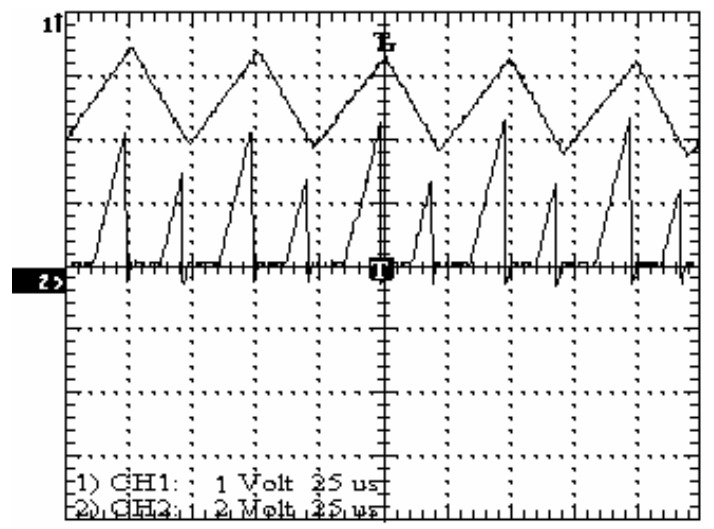

Ch1: 2A/div; Ch2: 2V/div; Time: $25 \mu /$ div.

Fig. 16. Filter inductor current and ramp voltage.

Fig. 17 shows the converter dynamic response to a $500 \mathrm{~W}$ to $1 \mathrm{~kW}$ step load variation. In this figure the output voltage, Vo, and the input current Ia are shown.

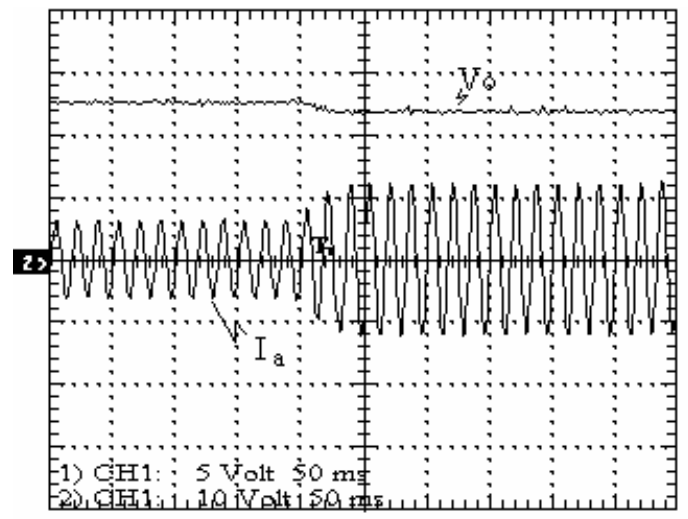

Ch1: 100V/div; Ch2: 10A/div; Time: 50ms/div.

Fig. 17. Converter Dynamic response.

\section{CONCLUSION}

This paper has presented a novel control technique that has the advantages of conventional hysteresis control and also constant switching frequency. The proposed control consists of a combination of the hysteresis control and PWM control, where constant switching frequency is obtained when a timer circuit is employed.

As can be seen from the experimental results, the switching frequency variation is small as expected according to the mathematical study. It is also possible to say that the frequency variation relative error decreases with the increase in switching frequency. As a result this effect could be negligible.

\section{ACKNOWLEDGEMENT}

The authors gratefully acknowledge CAPES, CNPq and FAPEMIG for the financial support in this work, and also Texas Instruments and ON Semiconductor for the sending of samples.

\section{REFERENCES}

[1] A.F. Souza, I. Barbi, "Retificadores de Alto Fator de Potência com Comutação Suave e Baixa Perda de Condução", pp. 01-10, SOBRAEP - julho de 1996. Vol. 1 - In Portuguese.

[2] O. Stihi and B.T. Ooi, "A Single-Phase ControlledCurrent PWM Rectifier," IEEE Trans. Power Electronics, vol. 3, no. 4, pp. 453-459 (1988).

[3] R. Toffano Jr., "Conversor Boost SR-ZVS-ZCSQRCPWM Operando com Fator de Potência Unitário Utilizando a Estratégia de Controle "Bang-Bang"; MSc Dissertation, UFU, 1997 - In Portuguese.

[4] R. Christiansen, "Analyzing and Controlling Harmonic Distortion", Power Techniques Magazine, November 1990, pp. 24-30.

[5] B. Wilkenson, "Power Factor Correction and IEC 5552", Power Techniques Magazine, February 1991, pp. 395.399.

[6] P.N. Enjeti and R. Martinez, "A High Performance Single Phase AC to DC Rectifier with Input Power Factor Correction", pp. 190-195, IEEE APEC'93 Conference Proceedings, 1993.

[7] J.W. Dixon, A .B. Kulkarni, M. Nishimoto, and B.T. Ooi, "Characteristics of a Controlled Current PWM Rectifier Link," pp. 685-691, IEEE, IAS, Conference Proceedings, 1986.

\section{BIOGRAPHIES}

Marcos Tadeu Galelli was born in Uberaba, Minas Gerais, Brazil, on December 28 ${ }^{\text {th }}$, 1977. He received the BSc and MSc degrees in Electrical Engineering from the Federal university of Uberlândia, Minas Gerais, Brazil, in 2003 and 2005 , respectively. He is currently with the National Service for Industrial Apprenticeship as an assistant professor and engineer. His research interest includes microcontrollers, robotics and control strategies applied to power converters. 
Márcio da Silva Vilela was born in Jiparaná, Rondônia, Brazil. He received the $\mathrm{BSc}, \mathrm{MSc}$ and $\mathrm{PhD}$ degrees in Electrical Engineering from the Federal university of Uberlândia, Minas Gerais, Brazil, in 1993, 1996 and 2004, respectively. $\mathrm{He}$ is currently with the Foundation for Superior Teaching of Rio Verde, Rio Verde, Goiás, Brazil. His research interest includes control techniques applied to static power converters, microcontrollers and high power factor rectifiers.

Ernane Antônio Alves Coelho was born in Teófilo Otoni, Brazil, on April 1, 1962. He received the B. S. degree in Electrical Engineering from Federal University of Minas Gerais, Brazil, in 1987 and the M. S. degrees from the Federal University of Santa Catarina, Florianópolis, Brazil, in 1989 and M. S. and Ph.D. degrees from the Federal University of Minas Gerais, in 2000. Presently he is a titular professor of the Electrical Engineering Faculty of the Federal University of Uberlândia, Brazil. His research interest areas include PWM inverters, factor correction circuits and new converters topologies and digital control using DSP's.

João Batista Vieira, Júnior was born in Panamá-Go, Brazil, on March 23, 1955. He received the B. S. degree in Electrical Engineering from Federal University of Uberlândia, Brazil, in 1980 and the M. S. and Ph.D. degrees from the Federal University of Santa Catarina, Brazil, in 1984 and 1991 respectively. He began work as Instructor of the Electrical Engineering Department at Federal University of Uberlândia (UFU) in 1980. Presently he is a titular professor of the Electrical Engineering Faculty of the Federal University of Uberlândia, Brazil. He has published around 210 papers. His research interest areas include highfrequency power conversion, modeling and control of converters, power factor correction circuits and new converters topologies. He is member of the SBA and member of the Brazilian Society of Power Electronics (SOBRAEP).

João Carlos de Oliveira was born in Passos, Brazil, in 1968. He received the B.Sc., M.Sc., and Ph.D. degrees from the Federal University of Uberlândia, Uberlândia, Brazil, in 1992, 1996, and 2001, respectively. In 2002, he joined the School of Electrical Engineering, Federal University of Uberlândia, where he is a Lecturer and also conducts research. His teaching and research interests are in new converters topologies, switched power amplifiers and softswitching techniques.

Luiz Carlos de Freitas was born in Monte Alegre de Minas-MG, Brazil, on April 1, 1952. He received the B. S. degree in Electrical Engineering from Federal University of Uberlândia, Brazil, in 1975 and the M. S. and Ph.D. degrees from the Federal University of Santa Catarina, Brazil, in 1985 and 1992 respectively. Presently he is a titular professor of the Electrical Engineering Faculty of the Federal University of Uberlândia, Brazil. He has published around 210 papers and he has two Brazilian patents pending. His research interest areas include high-frequency power conversion, modeling and control of converters, power factor correction circuits and new converters topologies. $\mathrm{He}$ is member of the SBA and member of the Brazilian Society of Power Electronics (SOBRAEP).

Valdeir José Farias was born in Araguari-MG, Brazil, on November $18^{\text {th }}, 1947$. He received the B. S. degree in Electrical Engineering from Federal University of Uberlândia (UFU), Brazil, in 1975 and the M. S. degree in Power Electronics from Federal University of Minas Gerais (UFMG) and Ph.D. degree State University of Campinas (UNICAMP), Brazil, in 1981 and 1989 respectively. Nowadays he is a titular professor of the Electrical Engineering Faculty of the Federal University of Uberlândia, Brazil. He has published around 210 papers. Prof. Farias research interesting area is Power Electronics in general, specially Soft-Switching Converters and Active Power Filters. He is member of the SBA and member of the Brazilian Society of Power Electronics (SOBRAEP). 